IUMRS-ICA 2008 Symposium “AA. Rare-Earth Related Material Processing and Functions” IOP Publishing IOP Conf. Series: Materials Science and Engineering 1 (2009) 012030 doi:10.1088/1757-8981/1/1/012030

\title{
Anode Properties of $\mathrm{LaSi}_{2} / \mathrm{Si}$ Composite Thick-Film Electrodes for Lithium Secondary Batteries
}

\author{
Hiroki Sakaguchi*, Takahisa Iida, Mamoru Itoh, Natsumi Shibamura, Tomoki \\ Hirono \\ Department of Chemistry and Biotechnology,Graduate School of Engineering, \\ Tottori University, 4-101 Minami, Koyama-cho, Tottori 680-8552, Japan \\ E-mail: sakaguch@chem.tottori-u.ac.jp
}

\begin{abstract}
LaSi}_{2}$ and $\mathrm{LaSi}_{2} / \mathrm{Si}$ composite as active materials for the negative electrode of lithium-ion battery were synthesized by mechanical alloying. Furthermore, thick-film electrodes prepared with a gas-deposition method by using these material powders, and their electrode performances were investigated. The $\mathrm{LaSi}_{2} \mathrm{GD}$-film electrode exhibited superb cycle stability, where more than $70 \%$ of the initial capacity was maintained for a period of 1000 cycles, though the initial capacity was only about $40 \mathrm{~mA} \mathrm{~h} \mathrm{~g}{ }^{-1}$. As for the $\mathrm{LaSi}_{2} / \mathrm{Si}$ composite electrodes, the original high discharge capacity of $\mathrm{Si}$ was retained even after several hundred cycles. The capacity after 300 cycles was $500 \mathrm{~mA} \mathrm{~h} \mathrm{~g}^{-1}$, which is larger than the theoretical capacity of graphite electrode practically used. Thus, we succeeded in developing the new composite electrode with both high discharge capacity of Si and good cyclability of $\mathrm{LaSi}_{2}$.
\end{abstract}

\section{Introduction}

It is considered that the lithium rechargeable batteries remain the most useful types of rechargeable batteries. However, since ever higher capacities are intensively pursued, metal-based materials are actively being researched as high-capacity substitutes for carbon-based materials[1-20].

$\mathrm{Si}$ is well known to have the highest capacity as an anode for the Li-ion battery, whereas it shows poor cycle stability owing to significant volume changes during lithium insertion-extraction, resulting pulverization of the particle[1,2]. To solve the problem, we focused on rare earth silicides, such as $\mathrm{LaSi}_{2}$, because they would exhibit good cycle life performance due to their large thermodynamic stabilities which must suppress the pulverization.

On the other hand, we have discovered that the cyclability of the electrode is remarkably improved if the electrode is prepared by using a gas-deposition (GD) method whereby the raw material powder placed in a guide tube is turned into aerosol by feeding it into an evacuated chamber together with argon gas, and a thick-film is created by projecting it through a nozzle on the substrate at high speed[9-11]. This method is expected to confer various advantages, including the production of electrodes exhibiting a strong adhesion between the particles of the active material as well as between the particles and the electron collector and so on. Therefore, we prepared thick film electrodes of rare earth silicides by using the GD method, and estimated their charge-discharge characteristics.

In order to prepare electrodes which combine the advantages of both $\mathrm{LaSi}_{2}$ and $\mathrm{Si}$, we considered whether it would be possible to synthesize a composite material consisting of $\mathrm{Si}$ particles with $\mathrm{LaSi}_{2}$. In this research, the $\mathrm{LaSi}_{2}$ and $\mathrm{Si}$ composite powder was synthesized by using a mechanical alloying 
IUMRS-ICA 2008 Symposium “AA. Rare-Earth Related Material Processing and Functions” IOP Publishing IOP Conf. Series: Materials Science and Engineering 1 (2009) 012030 doi:10.1088/1757-8981/1/1/012030

(MA) method. Then, we used the resulting material as the source material for the synthesis of a thickfilm electrode with the GD method. The electrochemical characteristics of the electrodes obtained were investigated.

\section{Experimental details}

A procedure of synthesis of rare earth silicide, $\mathrm{LaSi}_{2}$, as an active material is as follows. A mixture of elemental La chip and Si powder was put in a stainless steel vessel together with balls. The $\mathrm{Si} / \mathrm{La}$ atomic ratio was 2.0, and the weight ratio of the balls to the sample was about 15:1. The vessel used was sealed with an O-ring to keep an atmosphere of dry argon gas. Milling (MA) was done using a high-energy planetary ball mill at 300 r.p.m and at room temperature. As for the synthesis of $\mathrm{LaSi}_{2} / \mathrm{Si}$ composite powder, we used an excess amount of $\mathrm{Si}$ in comparison with the stoichiometric ratio of $\mathrm{LaSi}_{2}$ and used MA processing for both La and Si.

Figure 1 illustrates a schematic diagram of apparatus for gas-deposition and the conditions of deposition. The resulting powdered active materials, which are placed inside the tube, are turned into aerosol as they are carried into the evacuated chamber together with the carrier gas. After this, they are ejected at high speed through a nozzle and projected onto the substrate, i.e. $20 \mu \mathrm{m}$ thick $\mathrm{Cu}$ foil, to form the thick-film electrode. A photograph of $\mathrm{LaSi}_{2}$ thick-film electrode obtained is shown in Figure 2. The thickness of the film was not uniform but was $2 \sim 4 \mu \mathrm{m}$.

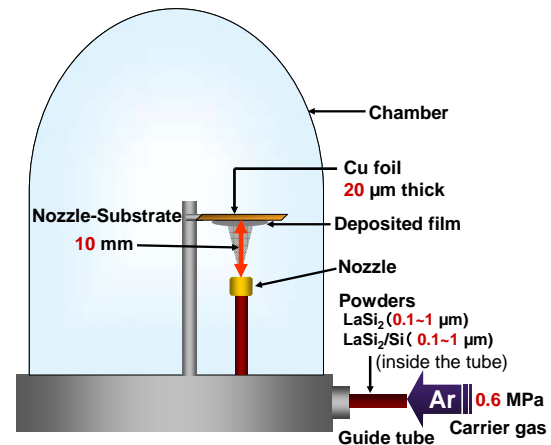

Figure 1 A schematic diagram of apparatus for gas-deposition.

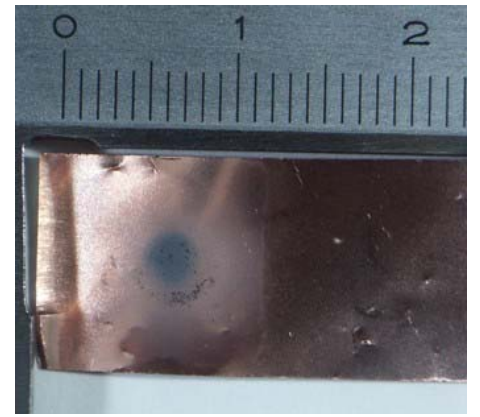

Figure 2 A photograph of $\mathrm{LaSi}_{2}$ thick-film electrode prepared by gas-deposition.

The electrochemical performance of each GD-film electrode was estimated with a galvanostat by using a three-electrode cell in $1 \mathrm{M} \mathrm{LiClO}_{4} / \mathrm{PC}$ (Propylene carbonate). Li metal sheets were used for both the counter and the reference electrode. The measurements were carried out at $0.1 \mathrm{~mA}$ for both charge and discharge at $303 \mathrm{~K}$. The cycling tests were conducted for voltages in the range of 0.005 to $2.0 \mathrm{~V}$.

\section{Results and Discussion}

Figure 3 represents the changes in the discharge ( $\mathrm{Li}$ extraction) capacity of $\mathrm{LaSi}_{2}$ thick-film electrode with respect to the number of cycles. The initial capacity of $\mathrm{LaSi}_{2}$ was only about $40 \mathrm{~mA} \mathrm{~h} \mathrm{~g}$, and it was found that the large capacity of elemental $\mathrm{Si}$ is not manifested in this silicide, as expected. However, the $\mathrm{LaSi}_{2}$ electrode exhibited superb cycle stability, where more than $70 \%$ of the initial capacity was maintained for a period of 1000 cycles.

Although Si has great potential capacity, it is unfavorable for the charge-discharge cycle stability. In order to prepare electrodes which combine the

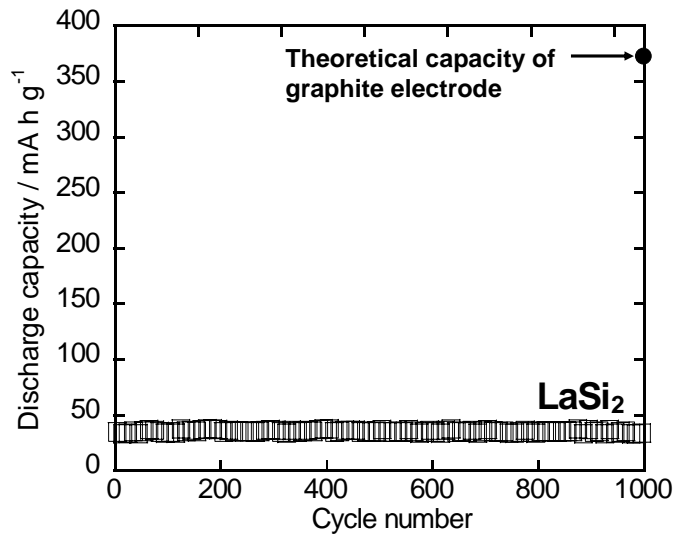

Figure 3 Changes in the discharge capacity of $\mathrm{LaSi}_{2}$ thick-film electrode with the number of cycles. 
IUMRS-ICA 2008 Symposium “AA. Rare-Earth Related Material Processing and Functions” IOP Publishing IOP Conf. Series: Materials Science and Engineering 1 (2009) 012030 doi:10.1088/1757-8981/1/1/012030

advantages of both $\mathrm{LaSi}_{2}$ and $\mathrm{Si}$, we considered whether it would be possible to synthesize a composite material consisting of Si particles with $\mathrm{LaSi}_{2}[11]$.

As for the processing of the powdered materials which were used as sources for preparing the composite $\mathrm{LaSi}_{2} / \mathrm{Si}$ electrodes, $\mathrm{LaSi}_{2}$ was prepared first with the MA method, after which Si powder was added and the mixture was stirred together lightly in a mortar. However, we were unable to obtain good performance for the electrode produced in this way. Therefore, after this, rather than following the stoichiometric ratios of $\mathrm{LaSi}_{2}$, we used an excess amount of Si and used MA processing for both $\mathrm{La}$ and $\mathrm{Si}$. As a result, compositing was realized at the level of individual particles.

Figure 4 shows the XRD pattern of the composite material prepared with the latter method. Since the patterns for both $\mathrm{LaSi}_{2}$ and Si were confirmed, it was clear that the target composite material was successfully synthesized.

The changes in the discharge capacity following the increase in the number of cycles of the $\mathrm{LaSi}_{2} / \mathrm{Si}$ composite GD-film electrodes are shown in Figure 5. As for the pristine Si thick-film electrode, the capacity suddenly decayed during 50 chargedischarge cycles. On the other hand, for the $\mathrm{LaSi}_{2} / \mathrm{Si}$ composite electrodes, the originally high discharge capacity of Si was retained even after several hundred cycles. The capacity after 300 cycles was $500 \mathrm{~mA} \mathrm{~h} \mathrm{~g}{ }^{-1}$, which is larger than the theoretical capacity of graphite electrode practically used.

Figure 6 displays the charge-discharge (Lithium

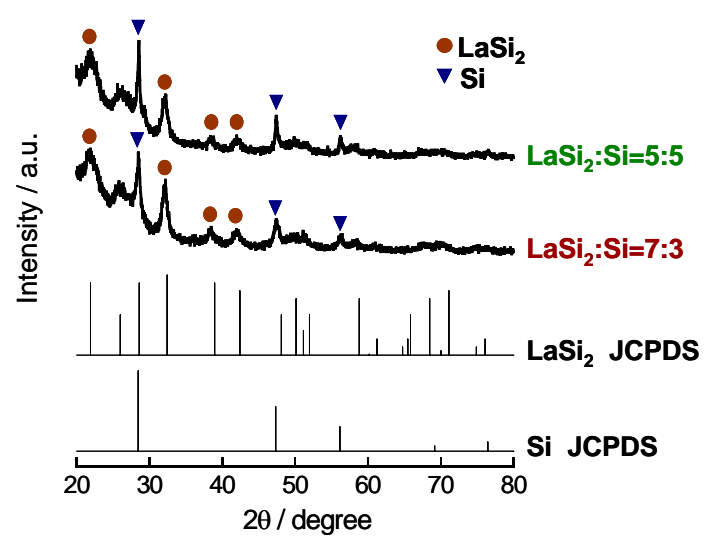

Figure $4 \mathrm{XRD}$ patterns of $\mathrm{LaSi}_{2} / \mathrm{Si}$ composite materials with different weight ratios of $\mathrm{LaSi}_{2}$ and Si.

insertion-extraction) curves of the first cycle for the $\mathrm{LaSi}_{2} / \mathrm{Si}$ composite GD-film electrodes to discuss the charge-discharge reaction. In all the electrodes, the plateau was observed at $0.4 \mathrm{~V}$ on the discharge curves, which corresponds to be due to the following reaction[1,2].Thus, it was clear from the matching of the charge-discharge potential that it is mainly Si that acts as the active material for these composite electrodes.

$$
\mathrm{Si}+4.4 \mathrm{Li}^{+}+4.4 \mathrm{e}^{-} \rightleftarrows \mathrm{Li}_{4.4} \mathrm{Si}
$$

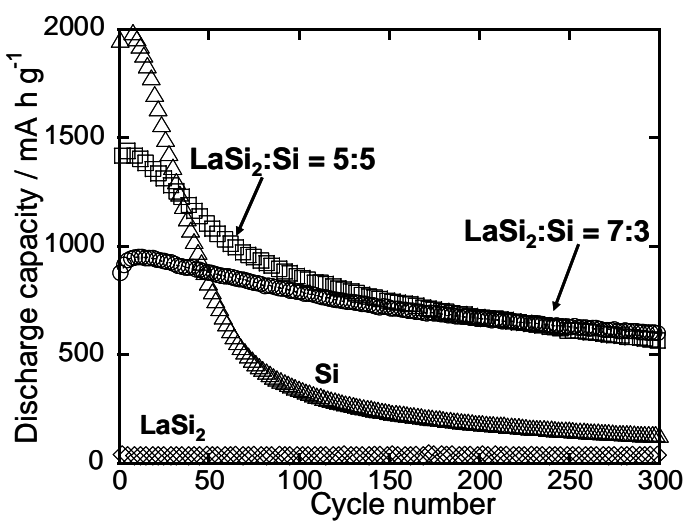

Figure 5 Changes in the discharge capacity of pristine $\mathrm{Si}$ and $\mathrm{LaSi}_{2} / \mathrm{Si}$ composite GD-film electrodes until 300th cycle.

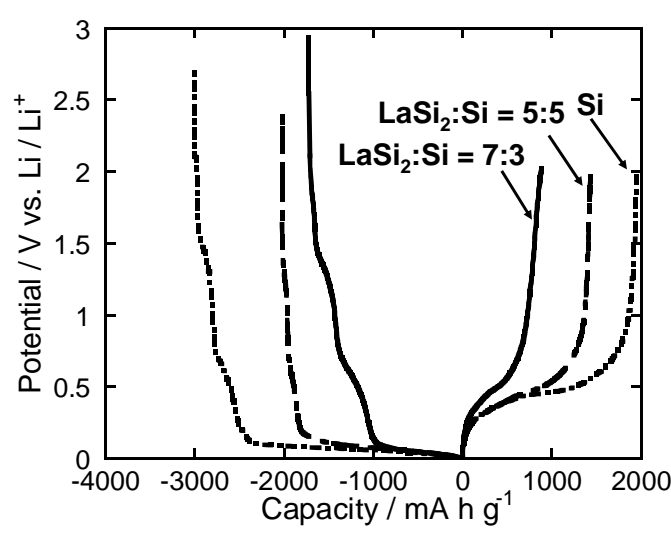

Figure 6 Charge-discharge curves of the first cycle for pristine $\mathrm{Si}$ and $\mathrm{LaSi}_{2} / \mathrm{Si}$ composite GD-film electrodes.

As shown in Figure 7, among the composite electrodes, the one in which the ratio of $\mathrm{LaSi}_{2}: \mathrm{Si}$ was $7: 3$ exhibited a large capacity of more than $900 \mathrm{~mA} \mathrm{~h} \mathrm{~g}^{-1}$ at the first cycle, and ca. $400 \mathrm{~mA} \mathrm{~h} \mathrm{~g}^{-1}$ even 
IUMRS-ICA 2008 Symposium “AA. Rare-Earth Related Material Processing and Functions” IOP Publishing IOP Conf. Series: Materials Science and Engineering 1 (2009) 012030 doi:10.1088/1757-8981/1/1/012030

at the 1000th cycle. Thus, we succeeded in developing the new electrode with both high discharge capacity of Si and good cyclability of the rare earth silicide. Their characteristics make them suitable for application as electrodes in embedded batteries for next-generation electric cars.

Figure 8 gives the result of changing the vertical axis in the Figure 7 from discharge capacity to Coulomb efficiency. The declination of the curves represents the peeling or detachment of the active material from the current collector ( $\mathrm{Cu}$ foil), and it was found that the declination was remarkably suppressed as the amount of $\mathrm{LaSi}_{2}$ became larger. Based on the fact that the composite electrode prepared in this way exhibited superior cyclability, we inferred that the $\mathrm{LaSi}_{2}$ phase surrounds the $\mathrm{Si}$ phase in individual composite particles and acts as a matrix which reduces the stress generated by the volumetric changes occurring in Si during the charge-discharge process.

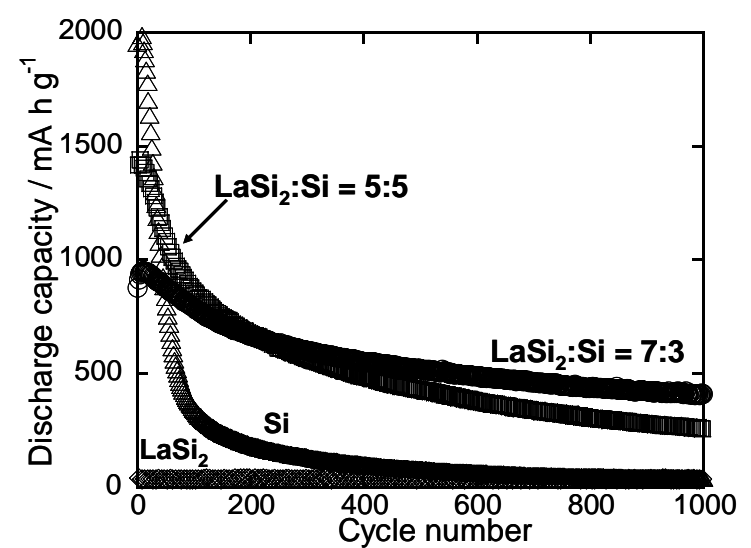

Figure 7 Changes in the discharge capacity of pristine $\mathrm{Si}$ and $\mathrm{LaSi}_{2} / \mathrm{Si}$ composite GD-film electrodes until 1000th cycle.

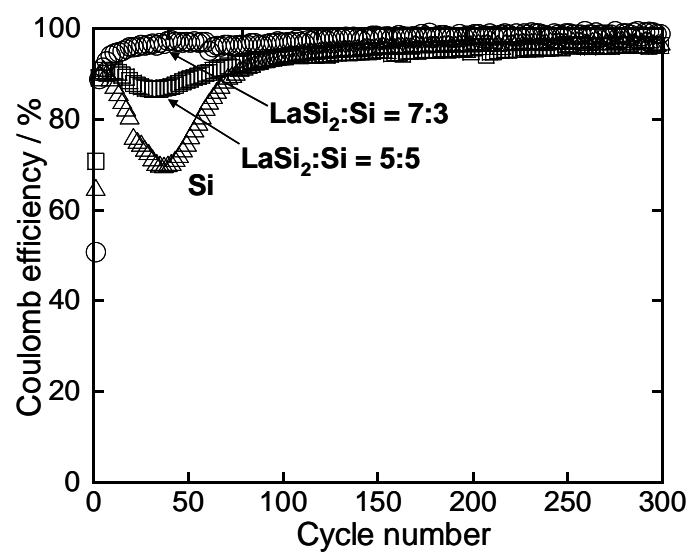

Figure 8 Changes in the Coulomb efficiency of pristine $\mathrm{Si}$ and $\mathrm{LaSi}_{2} / \mathrm{Si}$ composite GD-film electrodes with the number of cycles.
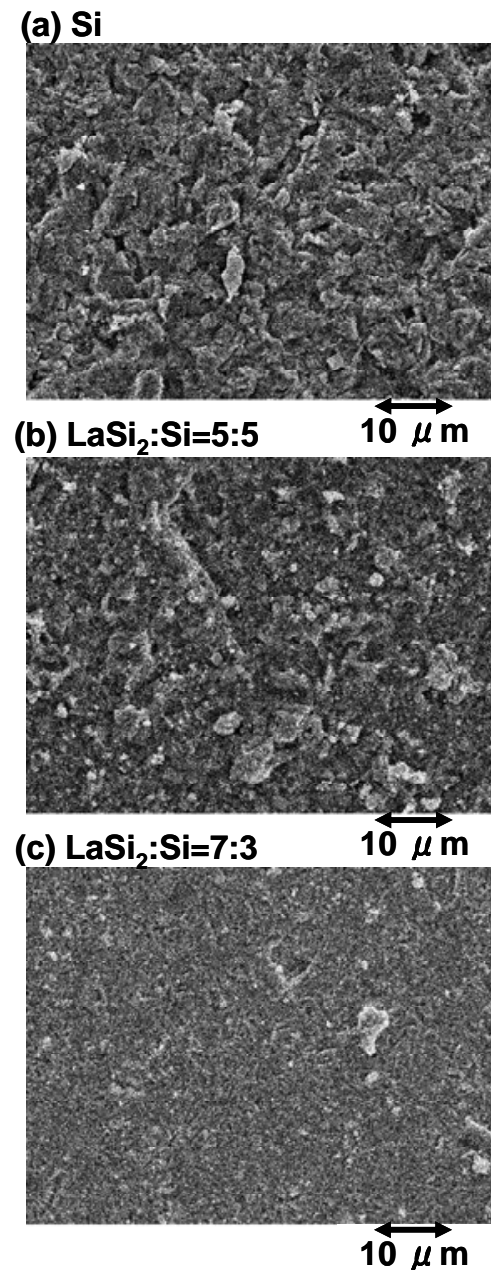

Figure 9 Surface SEM images of pristine Si and $\mathrm{LaSi}_{2} / \mathrm{Si}$ composite GD-film electrodes.

Figure 9 displays surface SEM images of the pristine $\mathrm{Si}$ and $\mathrm{LaSi}_{2} / \mathrm{Si}$ composite GD-film electrodes. In the composite electrode with $50 \mathrm{wt} \% \mathrm{Si}$ content (Figure 9(b)), the existence of the Si particles was obviously confirmed, so that the electrode exhibited poor cyclability. As for the composite electrode with $30 \mathrm{wt} \%$ Si content (Figure 9(c)), it was found that Si particles were homogeneously distributed in the composite electrode. At this optimum composition of $\mathrm{LaSi}_{2}$ and $\mathrm{Si}$ in the composite, each $\mathrm{Si}$ 
IUMRS-ICA 2008 Symposium “AA. Rare-Earth Related Material Processing and Functions” IOP Publishing IOP Conf. Series: Materials Science and Engineering 1 (2009) 012030 doi:10.1088/1757-8981/1/1/012030

particle was surrounded with $\mathrm{LaSi}_{2}$ layer, and the stress generated in the $\mathrm{Si}$ particle at $\mathrm{Li}$ insertionextraction was considered to be released by the $\mathrm{LaSi}_{2}$ layer because $\mathrm{LaSi}_{2}$ is more ductile than $\mathrm{Si}$.

\section{Conlusions}

We obtained the following information with respect to the anode characteristics of rechargeable lithium batteries comprising thick-film electrodes prepared with the GD method by using $\mathrm{LaSi}_{2}$ or $\mathrm{LaSi}_{2} / \mathrm{Si}$ composite powder as the source material. The $\mathrm{LaSi}_{2}$ electrode exhibited superior cycle stability, where the initial discharge capacity was maintained over 1000 cycles, though its capacity was not enough. We succeeded in developing the new composite electrode with both high discharge capacity of Si and good cyclability of a rare earth silicide $\mathrm{LaSi}_{2}$. We infer that the reason for the improvement in the cyclability results from the fact that $\mathrm{LaSi}_{2}$ reduces the stress generated by the immense volumetric changes occurring in the Si particles.

\section{Acknowledgement}

This work has been partially supported by a Grant-in-Aid for Scientific Research from the Ministry of Education, Culture, Sports, Science and Technology of Japan No. 19550179, and also Scientific Research of Priority Areas "Panoscopic Assembling and High Ordered Functions for Rare Earth Materials" No. 19018019.

\section{References}

[1] Chan C K, Peng H, Liu G, Mcilwrath K, Zhang X F, Huggins R A and Cui Y 2008 Nature Nanotechnology 3 31-5.

[2] Beattie S D, Larcher D, Morcrette M, Simon B and Tarascon J M 2008 J. Electrochem. Soc. 155 A158-63.

[3] Yang X, Wen Z, Huang S, Zhu X and Zhang X 2006 Solid State Ionics 177 2807-10.

[4] Ng S H, Wang J, Konstantinov K, Wexler D, Chew S Y, Guo Z P and Liu H K 2007 J. Power. Sources 174 823-7.

[5] Dimov N, Kugino S and Yoshio M 2003 Electrochim. Acta 48 1579-87.

[6] Park M S, Lee Y J, Han Y S and Lee J Y 2006 Mater. Lett. 60 3079-83.

[7] Kang Y M, Lee S M, Kim S J, Jeong G J, Sung M S, Choi W U and Kim S S 2007 Electrochem. Commun. 9 959-64.

[8] Sakaguchi H, Toda T and Esaka T 2005 Electrochemistry 73 505-8.

[9] Sakaguchi H, Toda T, Nagao Y and Esaka T 2007 Electrochem. Solid-State Lett. 10 J146-9.

[10] Takai S, Sakaguchi H, Tanaka K, Nagao Y and Esaka T 2008 Electrochemistry 76 293-6.

[11] Iida T, Hirono T, Shibamura N and Sakaguchi H 2008 Electrochemistry 9 644-8.

[12] Guo B, Shu J, Tang K, Bai Y, Wang Z and Chen L 2008 J. Power Sources 177 205-10.

[13] Hassoun J, Mulas G, Panero S and Scrosati B 2007 Electrochem. Commun. 9 2075-81.

[14] Todd A D W, Mar R E and Dahn J R 2007 J. Electrochem. Soc. 154 A597-604.

[15] Hassoun J, Panero S, Simon P, Taberna P L and Scrosati B 2007 Adv. Mater. 19 1632-5.

[16] Mukaibo H, Momma T, Mohamedi M and Osaka T 2005 J. Electrochem. Soc. 152 A560-5.

[17] Matsuno S, Kohno T, Takami N, Kawashima F and Sawa T 2005 Electrochem. Solid-State Lett. 8 A234-6.

[18] Trifonova A, Wachtlera M, Wagner M R, Schroettner H, Mitterbauer C, Hofer F, Möller K -C, Winter M and Besenhard J O 2004 Solid State Ionics 168 51-9.

[19] Wang L, Kitamura S, Obata K, Tanase S and Sakai T 2005 J. Power Sources 141 286-92.

[20] Stjerndahl M, Bryngelsson H, Gustafsson T, Vaughey J T, Thackeray M M and Edström K 2007 Electrochim. Acta 52 4947-55. 